Article

\title{
Impregnation of Wood with Microencapsulated Bio-Based Phase Change Materials for High Thermal Mass Engineered Wood Flooring
}

\author{
Damien Mathis ${ }^{1, * \mathbb{D}}$, Pierre Blanchet ${ }^{1} \mathbb{D}$, Véronic Landry ${ }^{1}(\mathbb{D})$ and Philippe Lagière ${ }^{2}$ \\ 1 Wood and Forest Science, University Laval, Quebec City, QC G1V 0A6, Canada; \\ Pierre.blanchet@sbf.ulaval.ca (P.B.); Veronic.landry@sbf.ulaval.ca (V.L.) \\ 2 Engineering and Mechanic Institute, University of Bordeaux, Bordeaux 33076, France; \\ philippe.lagiere@u-bordeaux.fr \\ * Correspondence: damien.mathis.1@ulaval.ca; Tel.: +33-768-144-329
}

Received: 7 December 2018; Accepted: 14 December 2018; Published: 19 December 2018

check for updates

Featured Application: High thermal mass engineered wood flooring.

\begin{abstract}
Wood is a porous material that can be impregnated and have enhanced properties. Two species of hardwood, red oak (Quercus rubra L.) and sugar maple (Acer saccharum Marsh.), were impregnated in a reactor with a microencapsulated phase change material. The objective was to enhance the thermal mass of wood boards used as surface layers for engineered wood flooring manufacturing. Preliminary experiments were conducted on small samples in order to define suitable impregnation parameters, based on the Bethell cycle. Thin wood boards were impregnated with a microencapsulated phase change material dispersed into distilled water. Several cycles of pressure were applied. Heating storage of the impregnated wood boards was determined using a dynamic heat flow meter apparatus method. A latent heat storage of $7.6 \mathrm{~J} / \mathrm{g}$ over $3{ }^{\circ} \mathrm{C}$ was measured for impregnated red oak samples. This corresponds to a heat storage enhancement of $77.0 \%$. Sugar maple was found to be harder to impregnate and thus his thermal enhancement was lower. Impregnated samples were observed by reflective optical microscopy. Microcapsules were found mainly in the large vessels of red oak, forming aggregates. Pull-off tests were conducted on varnished samples to assess the influence of an impregnation on varnish adhesion and no significant influence was revealed. Engineered wood flooring manufactured with impregnated boards such as characterized in this study could store solar energy and thus improve buildings energy efficiency. Although wood is a material with a low-conductivity, the thermal exchange between the PCM and the building air could be good enough as the microcapsules are positioned in the surface layer. Furthermore, flooring is an area with frequent sunrays exposure. Such high thermal mass EWF could lead to energy savings and to an enhancement of occupant's thermal comfort. This study aimed to characterize the potential of impregnation with MPCM of two wood species in order to make high thermal mass EWF.
\end{abstract}

Keywords: PCM; wood flooring; engineered wood flooring; thermal mass; microcapsules

\section{Introduction}

Wood is a widely used material in several industries such as construction and furniture. Its renewable nature, ease of transformation, and mechanical properties tend to make it the material of choice for several architects and designers. As wood is a porous material, it is possible to enhance its properties by impregnation or by the application of a coating. In recent decades, several treatments were applied on wood to enhance its durability [1], reduce its flammability [2], or increase its mechanical properties [3]. Such treatments can be opaque or translucent and can induce physical 
and/or chemical modifications within the wood. Impregnation can be achieved with pressure in a reactor. Several techniques were developed, such as Lowry, Rüping, or Bethell [4], and consist of different pressure cycles of pressure and/or vacuum.

Phase change materials (PCMs) are able to store a high amount of latent heat in a small material volume. Most of the time, this is achieved by a solid/liquid transition. Historically, paraffinic PCMs have been widely used $[5,6]$. Recently, multiple studies are focused on organic bio-based PCMs, for their better fire resistance [7], great chemical stability [8], and possibly low environmental impact [9]. Several studies found out that PCMs can increase the thermal mass of buildings and thus lead to a higher energy efficiency [10]. During the heating season, such materials are able to store solar energy within the day. This energy is then released at night, reducing the need of heating [11]. During the hot season, the PCMs can store the heat overflow and thus reduce the building's overheating [12]. With proper night conditions, the PCM can solidify and act again the next day. Implementing a PCM within a building is complex and multiple factors need to be considered, such as the climate, building architecture, and users' behavior. A good understanding of the melting and solidification dynamics is required to predict the PCMs behavior in buildings. Several studies are focusing on this point $[13,14]$. PCMs integrated in walls have already demonstrated potential benefits through multiple experimental studies $[15,16]$.

In order to be protected from the environment, PCMs need to be encapsulated. This also prevent any leakage when the PCM is in the liquid state. There are several ways to protect the PCM such as macroencapsulation, microencapsulation, or directly by molding a shape-stabilized material [8]. Microencapsulation has become a common way to protect the PCMs and thus to incorporate it in various components. Several techniques are used to manufacture microcapsules such as coacervation [17], interfacial polymerization [18], or spray-drying [19,20]. Capsules have to be strong enough to sustain the stress that is generated according to the volumetric change during the phase change process [21]. Urea-formaldehyde (UF) resin, melamine-formaldehyde (MF) resin, and polymers such as polyurethane (PU) are the most common shell materials for PCM microencapsulation [22].

There are a few trials of PCM composites using wood as a substrate. Jeong et al., proposed in 2012 to add microencapsulated PCMs (MPCMs) in a wood adhesive to enhance wood flooring thermal mass [23]. Bonding strength remained good, but thermal mass enhancement was low, due to the small quantity of MPCMs added in the glue (maximum 10\% of the glue mass). In 2016, Guo et al. shaped wood plastic composites by mixing microcapsules of dodecanol with wood flour and high-density polyethylene [24]. Their composites have shown a modulus of elasticity between 0.9 and $2.2 \mathrm{GPa}$, and $20.3 \mathrm{~J} / \mathrm{g}$ of latent heat. Increasing the ratio of MPCP would reduce the mechanical properties of the composite. In 2018, Mathis et al. prepared a decorative wood panel loaded with bio-based PCMs macroencapsulated in a polyethylene bag [25]. They obtained a panel with a maximum heat storage of $57.1 \mathrm{~J} / \mathrm{g}$. In 2016, Li et al., impregnated green fir wood (Pseudotsuga menziesii) with polyethylene glycol (PEG). PEG was dissolved into water and impregnation was achieved by soaking the samples into the solution at atmospheric pressure. They obtained a composite with a melting point of $26.74{ }^{\circ} \mathrm{C}$ and a latent heat of $73.59 \mathrm{~J} / \mathrm{g}$. They applied a surface coating to retain the PCM within the wood and conducted leaching tests. About $15 \%$ of the initial PEG content leached out after being immersed in water for two weeks [26]. In 2017, Barreneche et al. impregnated wood with paraffinic PCMs RT-21 and RT-27 from Rubitherm ${ }^{\circledR}$ [27]. They measured a latent heat of $20.62 \mathrm{~J} / \mathrm{g}$ for a weight proportion of PCM of $29.9 \%$. They applied a polystyrene solution in organic solvent to prevent the composite from any leakage when the PCM is in the liquid state. Sealing wood as they did can be hazardous as wood is a material that can undergo dimensional changes. In 2017, Vasco et al., conducted a kinematic characterization of the pressure-dependent PCM impregnation process for radiata pine wood samples [28]. They used octadecane, a paraffinic PCM. The impregnation of wood was achieved without applying any vacuum; the octadecane was forced deep into the wood under high pressure. They obtained a composite with a final PCM content of maximum $65.5 \%$. Composite stability was not 
assessed. It is highly possible that the PCM will leach out from the composite when in liquid state. In order to avoid this phenomena, PCM could be microencapsulated before the wood impregnation. Not any experiment of wood impregnation with PCM microcapsules seems to be referenced in literacy.

Engineered wood flooring (EWF) is a widely used floor covering solution. It can have different shapes but in most cases EWF is made of two parts: the lamella and the substrate. The substrate role is to ensure the mechanical strength of the assembly. It is also the thickest part; therefore it is usually made with a lower cost material than the lamella. The substrate can be made of MDF, HDF, plywood, particleboard, or solid wood. The lamella is the aesthetic face layer of the wood that is visible when installed, it is usually a sawn piece of timber. Sometimes a third layer is added; the counterbalancing layer that will enhance the mechanical properties of the assembly, specifically in order to avoid the bending. For this article, only the lamella was considered for impregnation, it is made from sawn timber. Thus, its porous microstructure could make possible the impregnation. Furthermore, it is the layer facing the interior air of the house, directly receiving the solar radiation for a maximum heat transfer. As if wood has a low thermal conductivity and can sometimes be considered as an insulation material, such an assembly with a PCM integrated in the innermost layer of the floor could higher the floor thermal mass and allow a sufficient thermal exchange.

Within a house, the floor receives a high quantity of solar energy. However, wood is a material often used as a flooring solution and embodies a limited thermal mass. In 1999, two-thirds of floor covering made of wood in Europe was EWF [29]. Consequently, impregnating EWF with PCM could enhance buildings' thermal mass and lead to energy efficiency and thermal comfort enhancements. This study aims on assessing the potential of impregnating wood with PCMs in order to make high thermal mass EWF.

\section{Materials and Methods}

\subsection{Materials}

\subsubsection{Phase Change Materials}

MPCMs Nextek29 were purchased from Microtek (Torrance, CA, USA). Nextek ${ }^{\circledR} 29$ are microcapsules filled with Puretemp ${ }^{\circledR} 29$ (Puretemp ${ }^{\circledR}$, Plymouth, MN, USA). Puretemp ${ }^{\circledR}$ PCMs are USDA certified $100 \%$ bio-based produced from agricultural sources. Exact composition is not known as these products are under patent protection. The shell of the microcapsule is, according to Microtek specs, a highly cross-linked MF-based resin with exact composition also under patent protection. Nextek ${ }^{\circledR} 29$ was bought in a wet cake form. It was composed by $69.61 \%$ of microcapsules and $30.39 \%$ of water.

\subsubsection{EWF Surface Layer}

Two wood species were selected, because of their large utilization in North America EWF market: red oak (Quercus rubra Marsh.) and sugar maple (Acer saccharum L.). Red oak is a porous species with a $0.52-0.61$ green density [30], where sugar maple is a diffuse species with a 0.52 green density [30]. These different wood properties can lead to different impregnation abilities. Wood lamellas were provided by a wood flooring manufacturer. They were produced using a frame saw, avoiding the need of sandblasting, and had a thickness of $3.5 \pm 0.3 \mathrm{~mm}$.

In practice, pieces of wood composing the EWF can have different widths, depending on the manufacturer and the customer's preferences. A thickness of $3.5 \mathrm{~mm}$ was chosen as it is a common in EWF industry for high-end products. 


\subsection{Methodology}

\subsubsection{Wood and MPCM Morphology}

The two woods species were characterized by optical microscopy (Leica, Wetzlar, Germany). Wood slices were cut using a microtome and colored with safranin. Vessels size was measured using the software Wincell. The diameter of the MPCM was also evaluated by optical microscopy. Microcapsules were dispersed in water and dropped between two glass lamellas. Mean diameter measurement was conducted over 288 microcapsules. After impregnation, microcapsules were observed within the wood by optical reflective microscopy, with an Axio Imager M.2 (Zeiss, Oberkochen, Germany).

\subsubsection{Wood Impregnation}

Impregnation was achieved using Nektek $^{\odot} 29$ microcapsules dispersed into distilled water. The microcapsules were beforehand dispersed by mechanical stirring in water for $30 \mathrm{~min}$ at $50{ }^{\circ} \mathrm{C}$. Various microcapsules concentrations were experimented (from 10 to $50 \mathrm{wt}$ \%). Before impregnation, each wood sample was kept stabilized in a room with a controlled humidity of $42 \%$ and a temperature of $20{ }^{\circ} \mathrm{C}$. At the conditions the wood theoretically has an equilibrium moisture content of $8 \%$. After each impregnation, samples were replaced in the same room until constant weight was reached. Even if the samples were stabilized in the same room before and after impregnation, it is not possible to assess that they had the same relative humidity at each step. Indeed, the moisture content of wood is subject to an hysteresis when raised and then reduced [31]. The moisture content of the re-stabilized sample will likely be higher. In order to characterize the weight gain that is due to the PCM deposit within wood, reference samples were impregnated with pure distilled water. The moisture content hysteresis was determined. Therefore, weight gain of the samples is presented in the results section and was adjusted after this weight hysteresis, due to remaining water within wood.

Preliminary experiments were conducted on samples sized $10 \times 50 \times 4 \mathrm{~mm}$ within a $2 \mathrm{~L}$ reactor (Paar, Ashland, VA, USA) in order to determine suitable impregnation parameters. Several parameters were varied, such as pressure, temperature and microcapsules concentration into water. Larger scale wood boards sized $210 \times 70 \times 4 \mathrm{~mm}$ were impregnated with $18.9 \mathrm{~L}$ reactor (Paar, Ashland, VA, USA).

\subsubsection{Heat Storage}

Heat storage measurements were conducted on the wood boards with a dynamic heat flow meter apparatus (DHFMA) according to ASTM C1784. Measurements were conducted with a Lasercomp Fox FX314 (TA instruments, New Castle, DE, USA), from $18{ }^{\circ} \mathrm{C}$ to $40.5^{\circ} \mathrm{C}$ with a temperature step of $1.5^{\circ} \mathrm{C}$. The methodology used was similar than the one used by Damien et al. in 2018 [25], but with higher temperature steps, as the thickness of the samples allowed a $1.5^{\circ} \mathrm{C}$ step without saturation. According to the Fox FX314 requirements, measurements were conducted on $255 \times 250 \times 4 \mathrm{~mm}$ surfaces. Each surface of test was constituted by three large wood boards as described previously, which were assembled side-by-side with PVA adhesive, as shown in Figure 1.

\subsubsection{Pull-Off Adhesion Tests}

As some microcapsules will fill the wood, it is important to ensure whether if a varnish could still be applied to the wood and have a good adhesion. For this purpose, pin-pull tests were conducted in the spirit of the ASTM test method D4541 standard test method for pull-off strength of coatings using portable adhesion testers. Impregnated and control samples were coated with a UV-curable high solids acrylate coatings from $\mathrm{CANLAK}^{\odot}$ (Daveluyville, QC, Canada). Control samples were of two types: either wood without any treatment, either wood impregnated with water only. This methodology allows to study the influence of water impregnation on varnish adhesion. The pull-off tests were only conducted with the red oak samples as the sugar maple did not show a great potential of impregnation. Coating was applied using a roller coater. Seven coating layers of around 15 microns were applied. Between each paths, polymerization was induced using a UV-oven. A light sandblasting with P220 
paper was applied before the last layer. Final coating thickness was of $0.11 \pm 0.03 \mathrm{~mm}$. Bi-compound epoxy glue from the company Lepage (Don Mills, ON, Canada) was applied to fix the pins, with a curing time of $24 \mathrm{~h}$. Tests were conducted with a $5 \mathrm{~K}$ Newton universal testing machine with a rate of pull of $10 \mathrm{~mm} / \mathrm{min}$. The adhesive strength values were measured to characterize the varnish adhesion on the different samples. Tests were achieved with 28 repetitions of standard red oak, 28 repetitions of red oak impregnated with water only, and 28 repetitions of red oak impregnated with water and PCM.

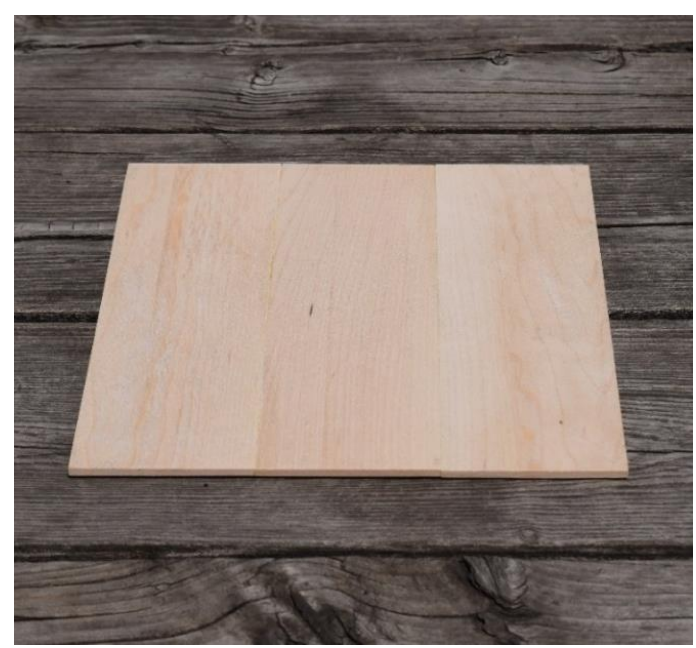

Figure 1. Surface for thermal testing, constituted by three glued wood boards.

\section{Results}

\subsection{Morphology of the Components}

\subsubsection{Wood Morphology}

A cross section of red oak and sugar maple are shown in Figure 2a. Red oak is a porous wood with initial wood vessels substantially larger than in final wood. Small vessels have an average diameter of 66.6 microns with a minimum of 42.9 microns. Big vessels have an average diameter of 286.7 microns with a minimum of 237.2 microns. A cross section of sugar maple is shown in Figure 2b. Sugar maple is a wood with diffuse pores. They have an average diameter of 58.1 microns with a minimum of 26.9 microns. Sometimes, the vessels are grouped, leading to smaller diameter vessels.

\subsubsection{PCM Microcapsules}

A micrograph of Nextek29 is shown in Figure 3. First observation is that microcapsules tend to form aggregates.

PCM microcapsules Nextek $29^{\odot}$ had an average size of 8.4 microns with a standard deviation of 6.1 microns. Size repartition is shown in Figure 4.

The average size of the vessels was 66.6 microns and 58.1 microns for red oak and sugar maple respectively. According to these results, the microcapsules are smaller and could be able to fill the vessels of both wood species.

\subsection{Impregnation of Small Samples}

Weight enhancement after impregnation of small samples was assessed for impregnations with several PCM concentrations. Results for both species are shown in Figure 5. 


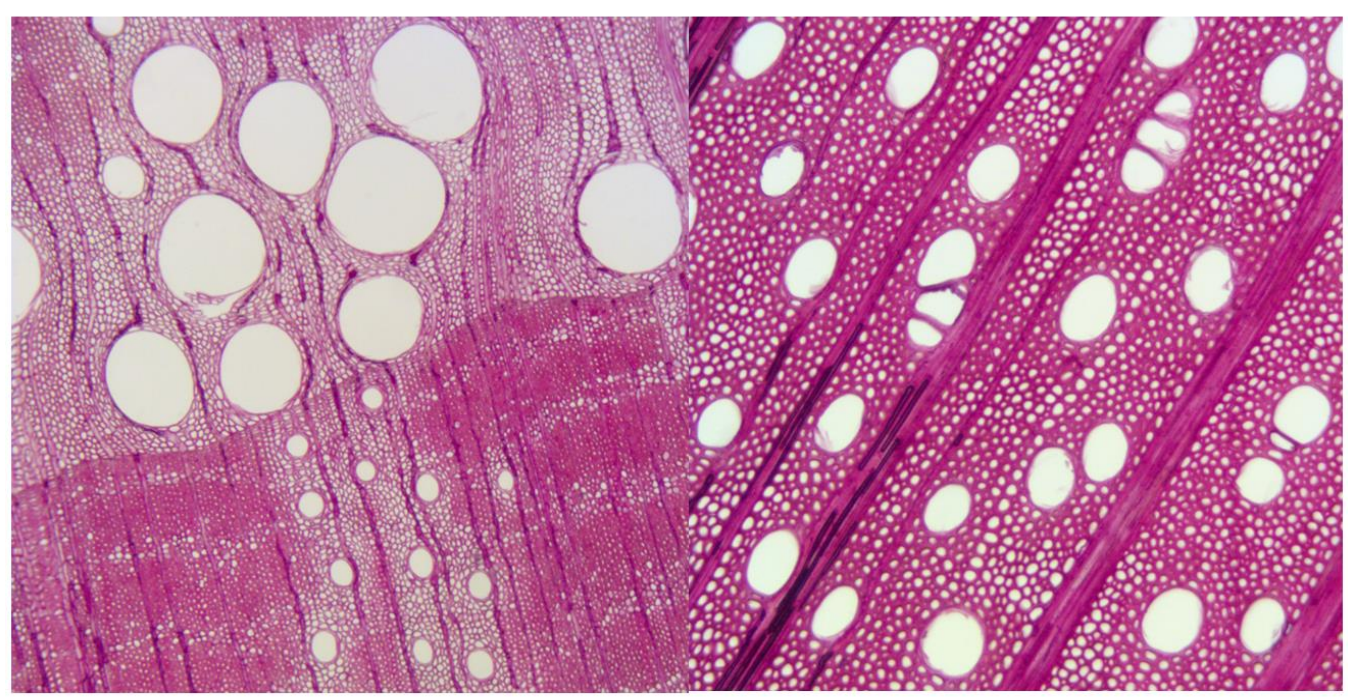

(a)

(b)

Figure 2. Wood morphology before impregnation. (a) Red Oak; (b) Sugar maple.

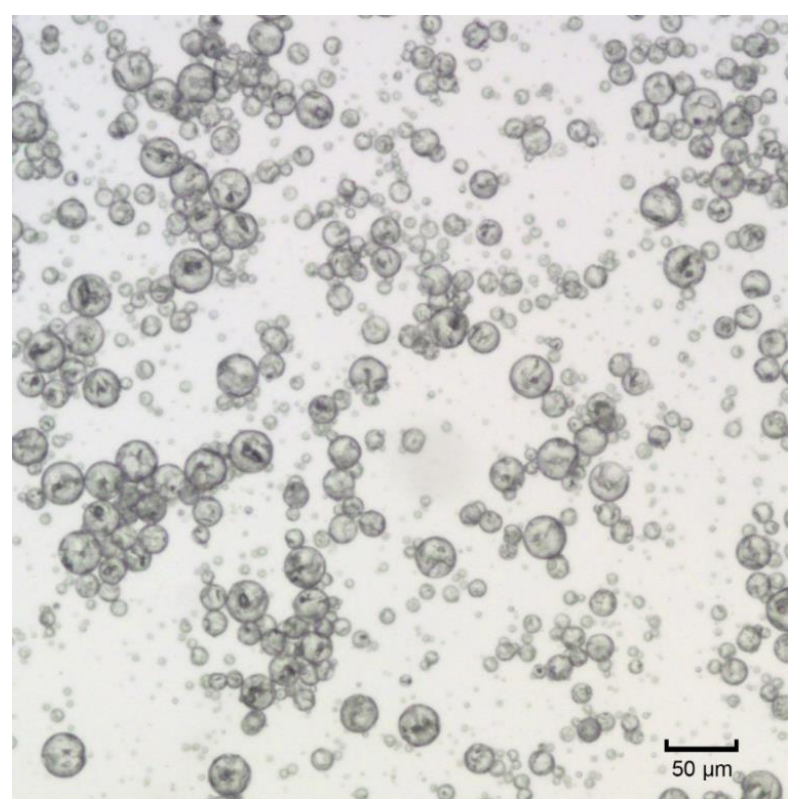

Figure 3. Observation of microcapsules by optical microscopy $100 \times$.

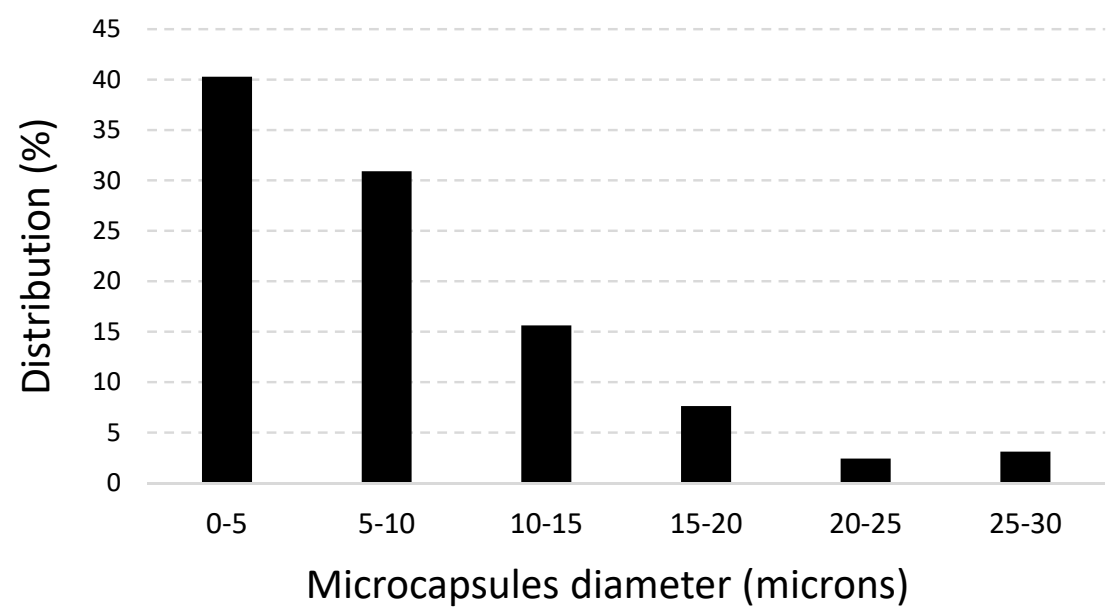

Figure 4. Distribution of Nextek29 ${ }^{\odot}$ microcapsules size. 


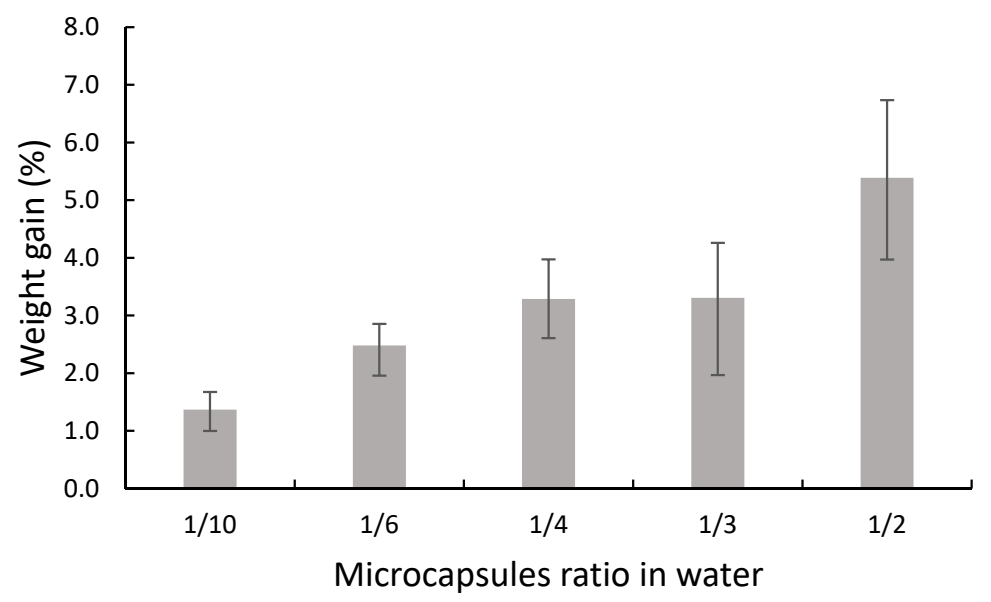

Figure 5. Weight enhancement for several microcapsules ratios.

Increasing the PCM concentration into water increases the weight gain after impregnation. A maximum of $5.4 \pm 1.4 \%$ of weight gain was measured for a $50 \%$ mass ratio of microcapsules into water. Weight enhancement after impregnation of small samples was measured for several pressures and several concentration into water. Results for both species are shown in Figure 6.

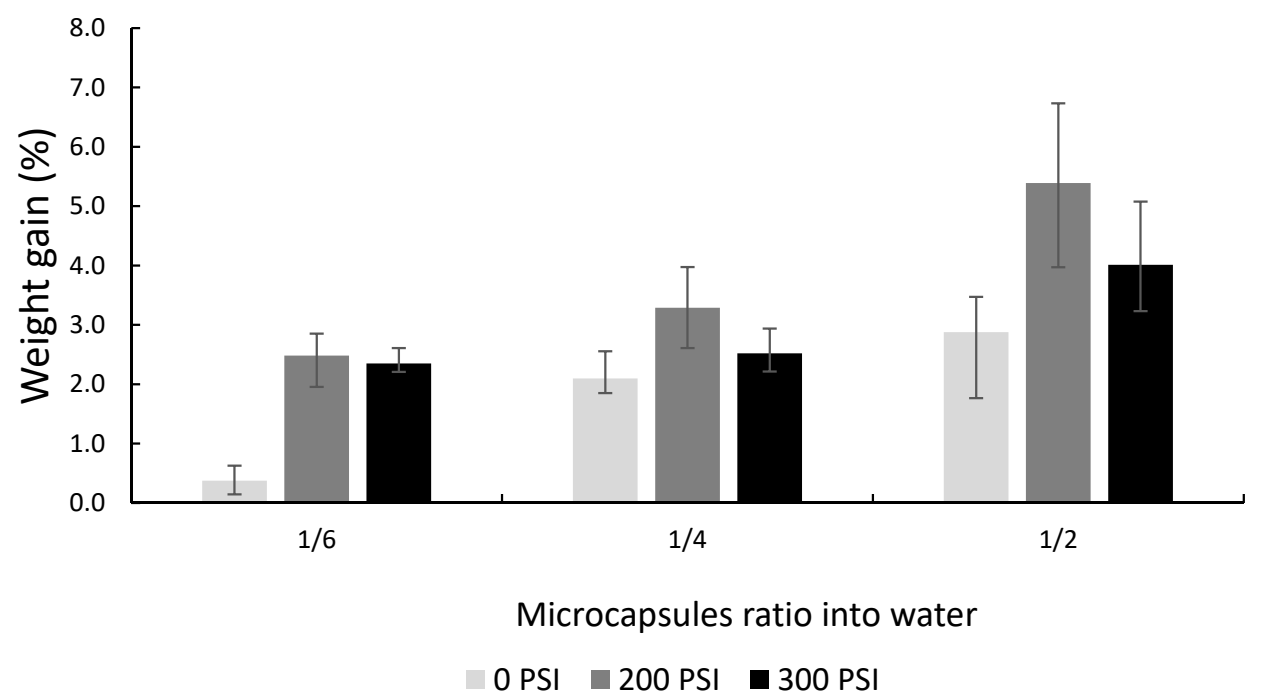

Figure 6. Weight enhancement of small samples for several pressures.

\subsection{Impregnation of Wood Boards}

\subsubsection{Morphology}

Micrographs of red oak impregnated with MCPMs are shown in Figure 7. Microcapsules are clearly visible, filling some initial wood big vessels, as shown in A. The microcapsules seems to merge in aggregates in some of the vessels. Sometimes there is also a small quantity of MPCM at the periphery of a big vessel, as shown in B.

Most of the small vessels of red oak were not containing any microcapsules, as visible in Figure 8a, in C. However, a few vessels were containing a small quantity of microcapsules, as visible in Figure 8b, in E. Some microcapsules were also observed over red oak fibers, as shown in D. Cutting the samples for observation could have displaced some microcapsules. The small vessels were mostly empty, as if the microcapsules size (8.4 microns) is, in average, widely inferior than the final wood small vessels average size (66.6 microns). 


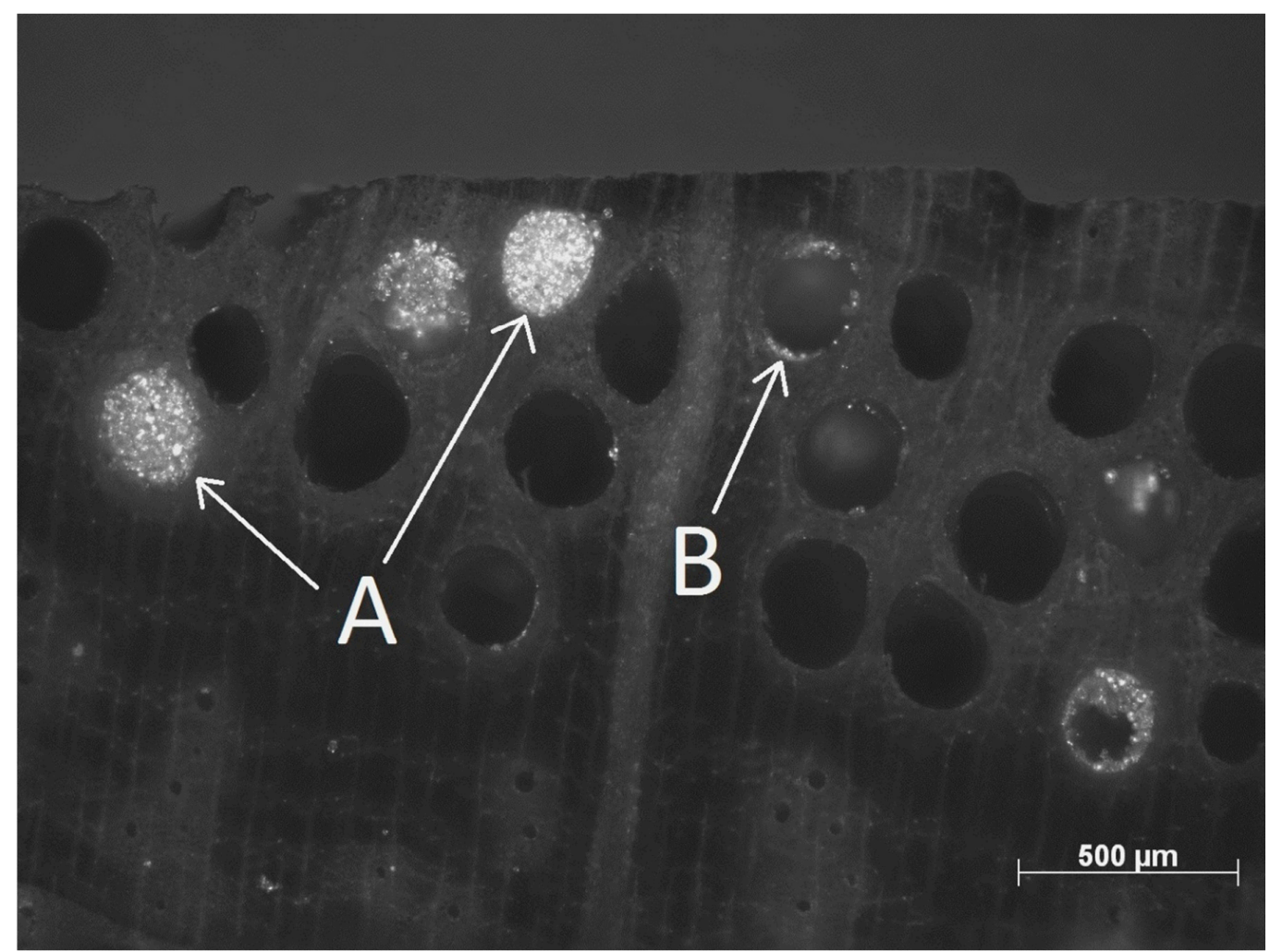

Figure 7. Red oak impregnated with MPCM.

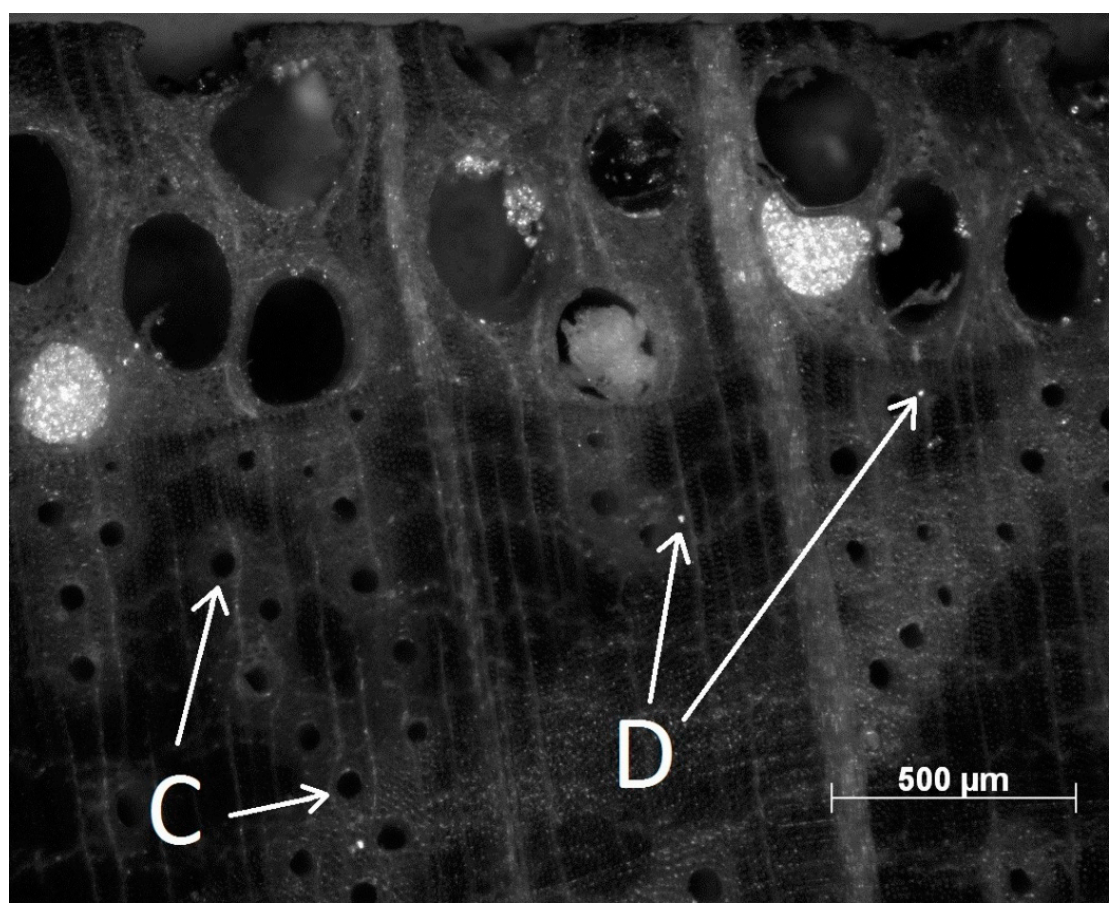

(a)

Figure 8. Cont. 


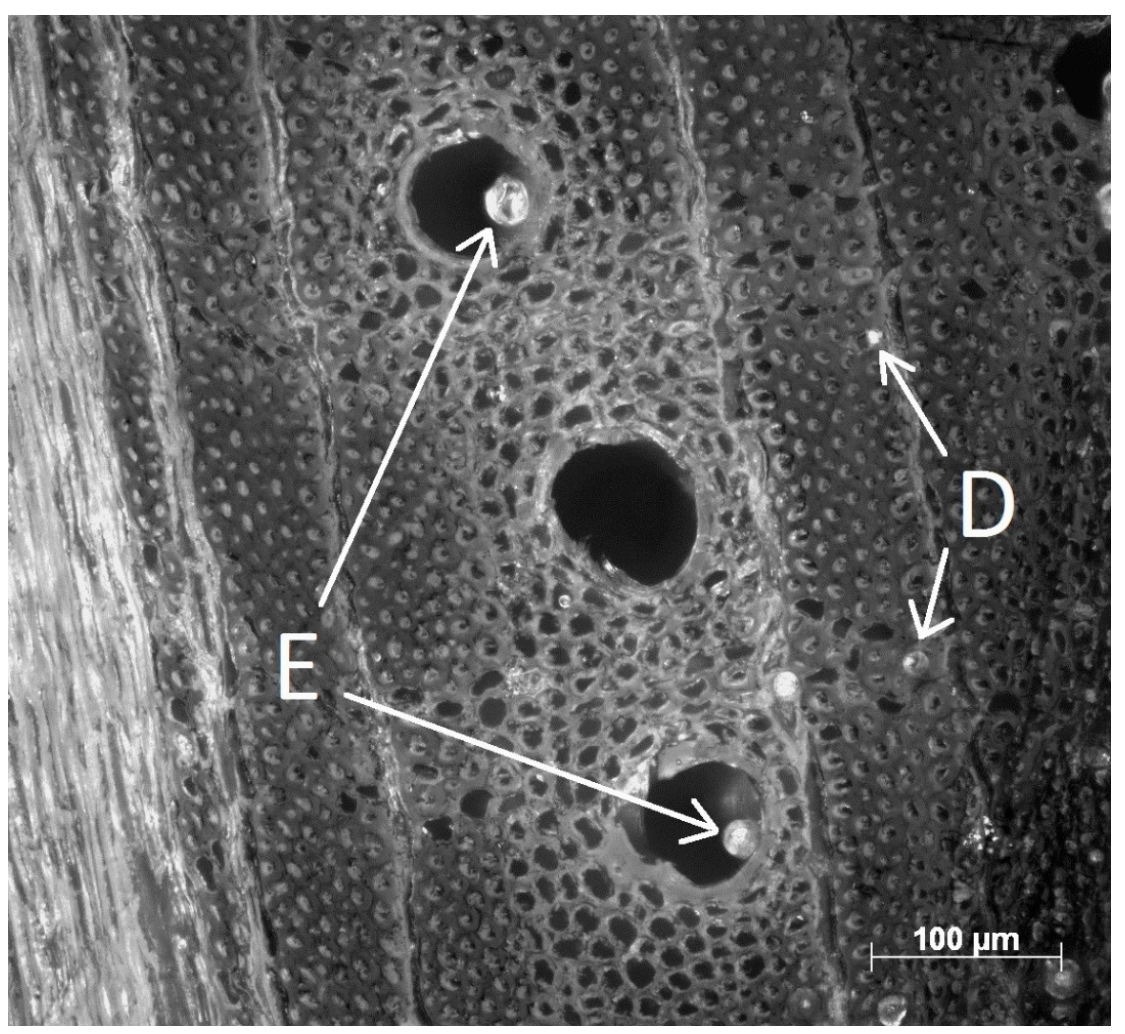

(b)

Figure 8. Impregnated red oak microscopy. (a) Small late wood vessels are mostly empty; (b) Some small vessels are filled with a few microcapsules.

Only some of the big vessels are filled with the MPCM. As no other study of wood impregnation with microcapsules was found in literature, there is not any other results to compare with and help understand this phenomenon. Yet, red oak big vessels are sometimes clogged by tyloses. The tyloses could block the progression of microcapsules, and as a consequence, some of the vessels would stay empty. In this case, dissolving the tyloses before impregnation could lead to a larger quantity of filled vessels. In 2018, Jiang et al., improved poplar sapwood permeability by autohydrolyze coupled with a sodium hydroxide treatment [32]. They found a partial dissolution of tyloses while the skeletal structure of the fiber and vessel cell walls remained intact. This could be an efficient way to remove red oak tyloses. However, such treatment could lead to wood degradation. As making wood flooring required a wood of good appearance, this could be a limit. Yet, further experiments would be required to have a better understanding of microcapsules distribution within red oak.

Micrographs of the sugar maple impregnated with MCPMs are shown in Figure 9. Only a few vessels were containing microcapsules, as visible in $\mathrm{F}$.

For both woods, only a few small vessels were containing microcapsules. Still, these vessels are, in average, much larger than the capsules and should be able to be filled. An explanation could from the poor dispersion of the microcapsules in the impregnation liquid. As observed by microscopy, the capsules tend to form aggregates. These aggregates could be too big to fill the small vessels, explaining the small amount of capsules in it.

The impregnated wood boards were cut and observed at several locations within the treated volume. Microcapsules were found in each zone. It indicates that the microcapsules are able to fill the central part of the wood boards. Indeed, the boards are cut so the vessels are oriented according to the length direction. Thus it may have been difficult for the microcapsules to reach the middle of the boards. Still, it is difficult to quantify how much microcapsules are filling the different parts of the samples. 


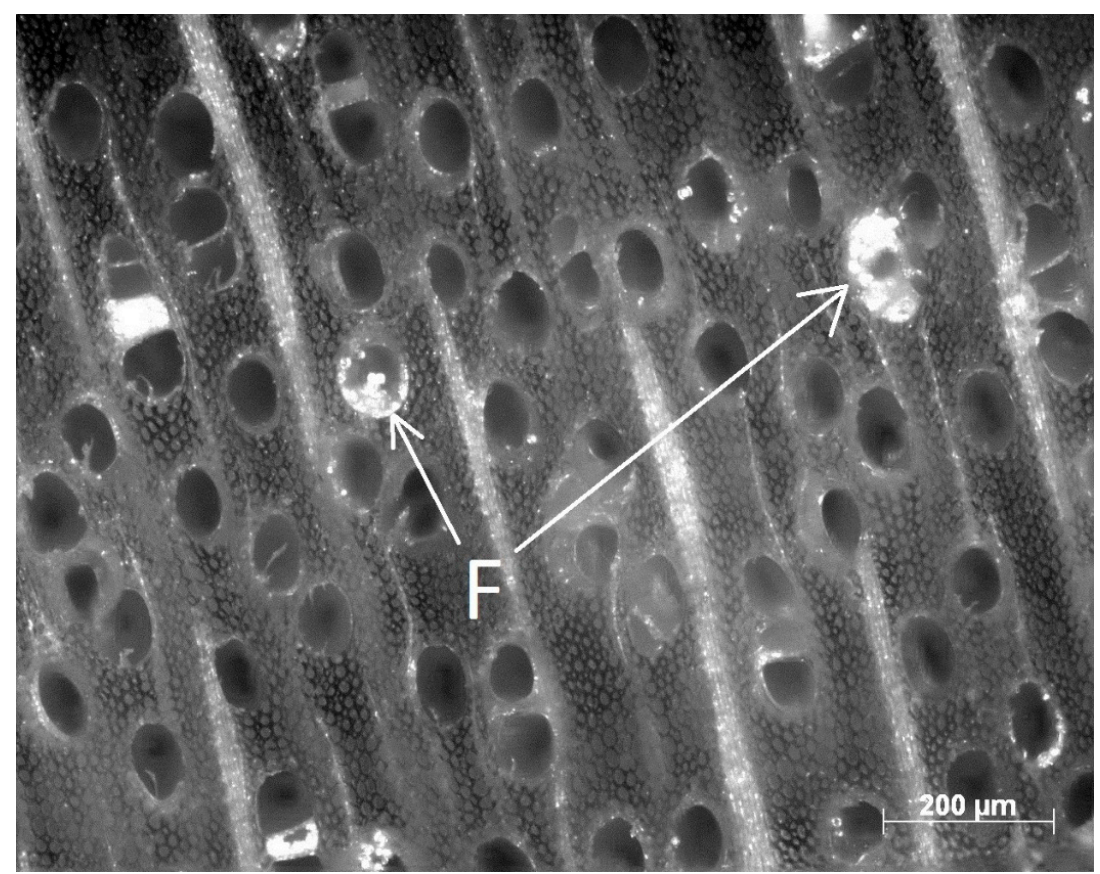

(a)

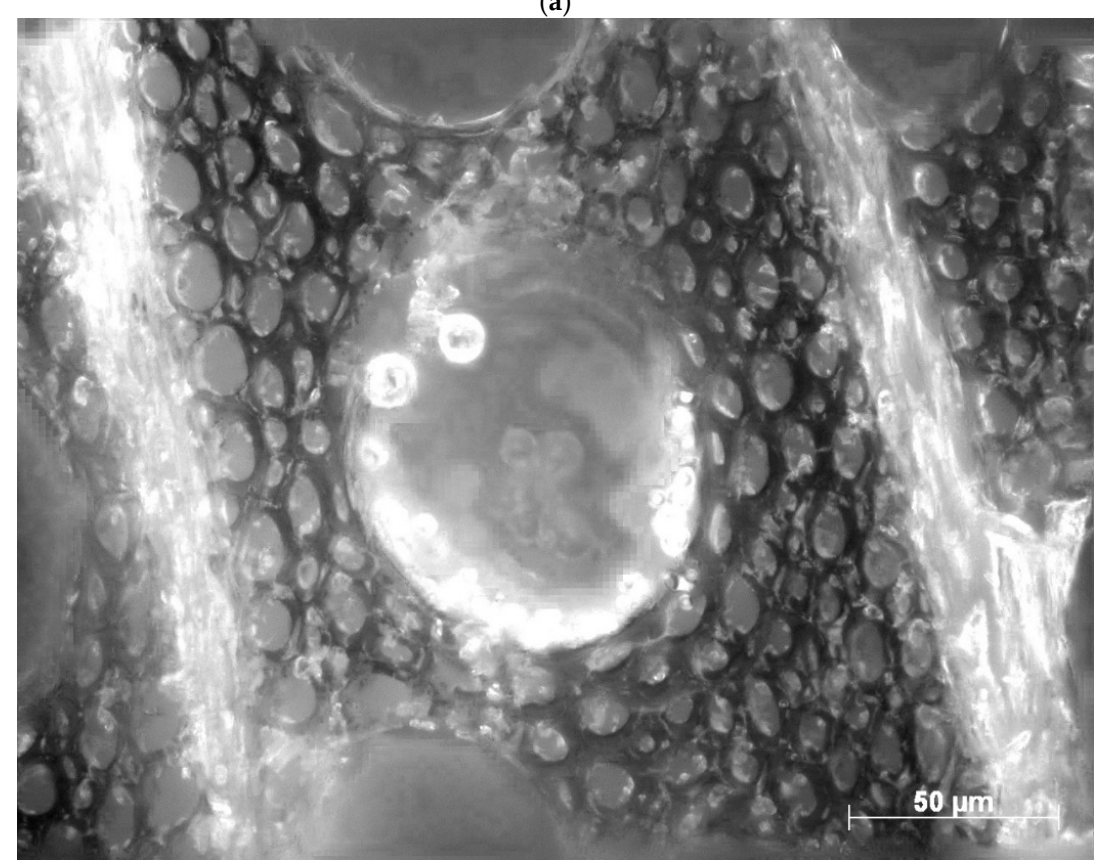

(b)

Figure 9. Impregnated sugar maple microscopy. (a) Sugar maple vessels containing microcapsules. (b) Zoom on the microcapsules.

\subsubsection{Heat Storage}

Average heating storage capacity of impregnated and control red oak boards is shown in Figure 10. 


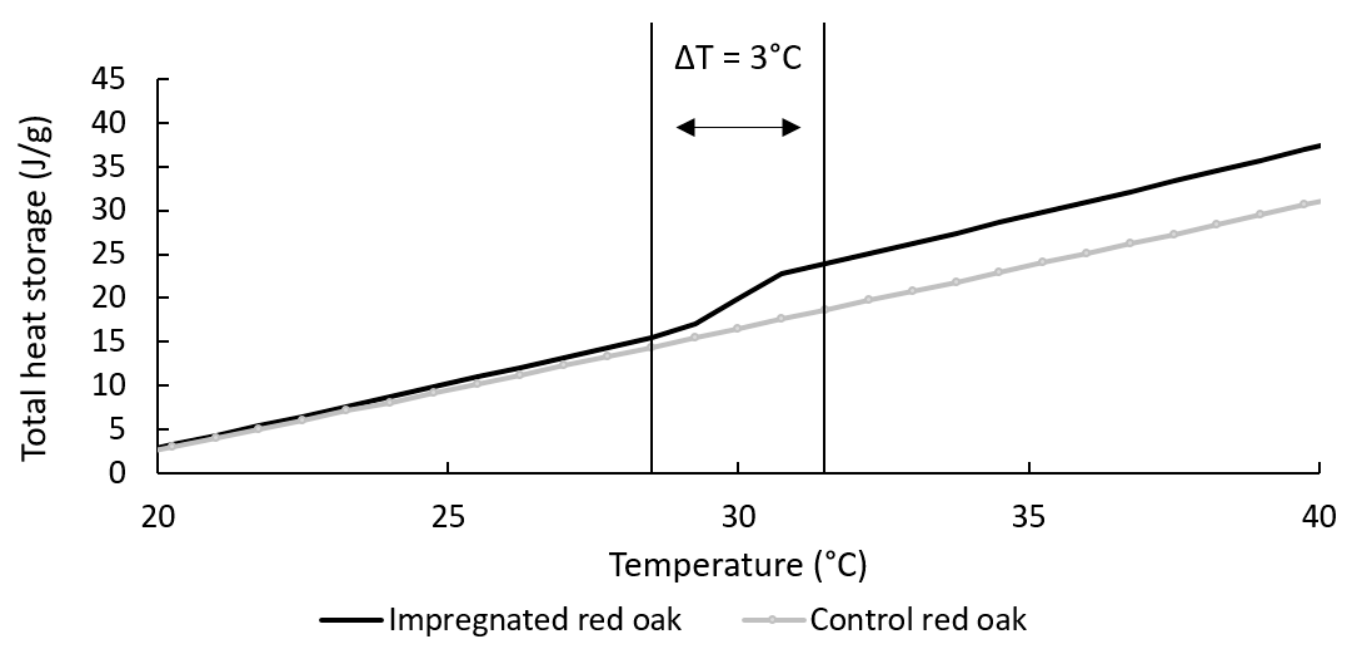

Figure 10. Heat storage capacity of red oak, melting cycle.

Between $28.5^{\circ} \mathrm{C}$ and $31.5^{\circ} \mathrm{C}$, the total heat storage of red oak is of $7.6 \mathrm{~J} / \mathrm{g}$. This corresponds to a thermal mass enhancement of $77 \%$. A second observation is that the specific heat $(\mathrm{CP})$ of red oak is higher for the impregnated wood. The first reason could be that the microcapsules densify the wood and thus contribute to its specific heat. In addition, as described earlier, the impregnated samples have a moisture content higher than the control samples, due to an hysteresis phenomenon [31]. These two phenomena can enhance the impregnated wood specific heat.

A comparison of melting and solidification cycles of red oak is shown in Figure 11.

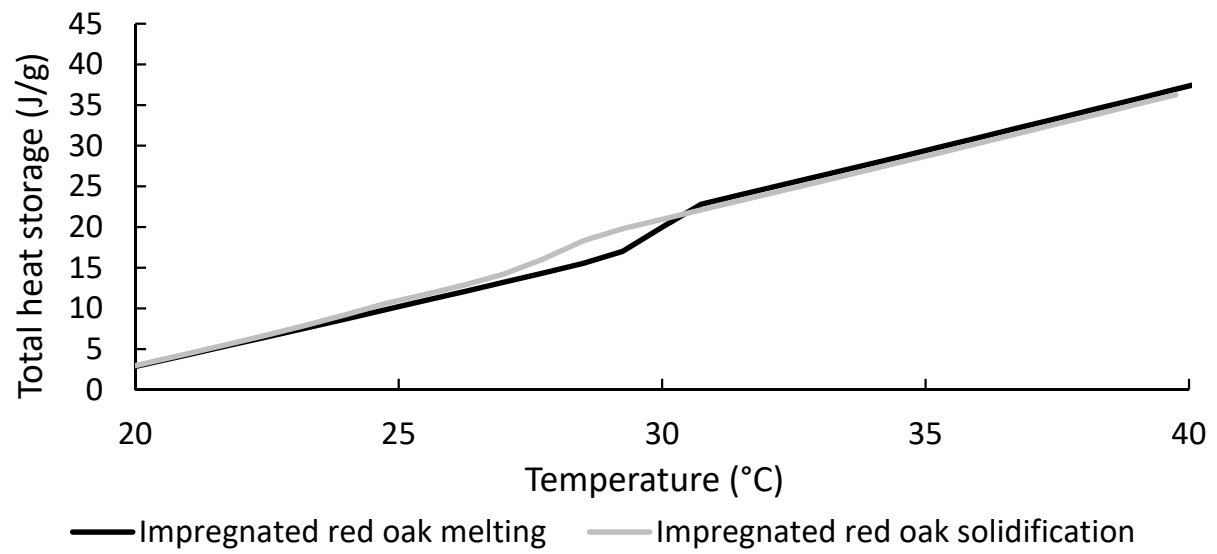

Figure 11. Comparison of impregnated red oak melting and solidification.

A first observation is that the MPCM is subject to supercooling. This is an usual observation for organic phase change materials [6]. Another observation is that the melting heat is a little bit higher than the solidification heat. The same phenomena was observed by wood/PCM samples in 2018 by Mathis et al. When the melting cycle begins, the sample is first stabilized at $20^{\circ} \mathrm{C}$ and heated to a maximum of $40{ }^{\circ} \mathrm{C}$. In addition, dry air is flowing through the test chamber in order to avoid the moisture to condensate on the sensors. Heating the samples may reduce their moisture content. Some samples were weighted before and after a melting test to stud this phenomena and an average difference of weight of $1.5 \%$ was measured. It is possible that the moisture vaporization during the melting cycle contributes to the total heat measured. This could explain the higher total heat storage of the wood for the solidification cycle.

Heating storage capacity of impregnated and control sugar maple boards is shown in Figure 12. 


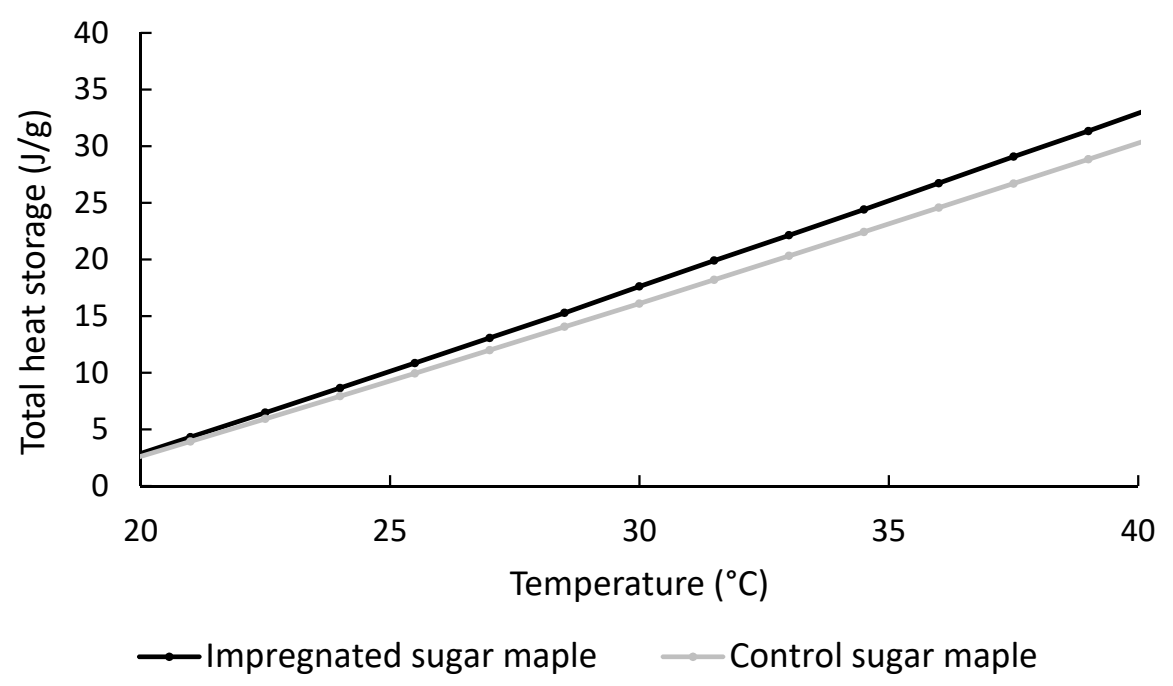

Figure 12. Heat storage capacity of sugar maple, melting cycle.

First observation is that the latent heat storage of impregnated sugar maple is low around $29^{\circ} \mathrm{C}$. Between $28.5^{\circ} \mathrm{C}$ and $31.5^{\circ} \mathrm{C}$, the total heat storage is of $4.5 \mathrm{~J} / \mathrm{g}$. This corresponds to a thermal mass enhancement of $7.1 \%$. This results confirms the preliminary tests and goes along the reflective optical microscopy observations for this wood.

\subsubsection{Adhesion of a UV-Curable Coating Formulation}

Results of pull-off adhesion tests are shown in Figure 13.

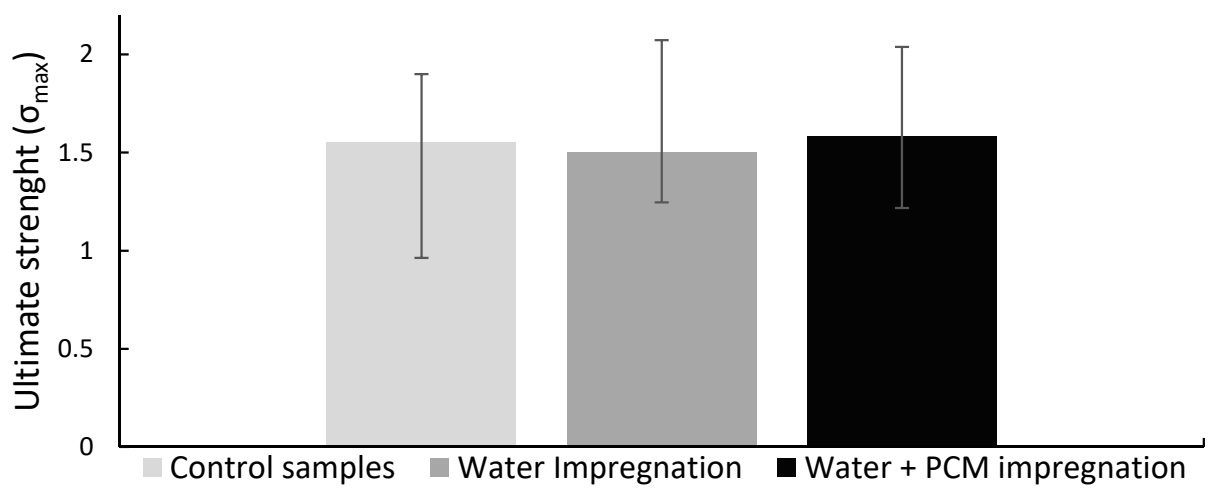

Figure 13. Average coating adhesive strengths for different samples.

Average ultimate strength of control, water impregnated, and water + PCM impregnated samples were of 1.55, 1.50, and 1.58 MPa respectively. According to these results, either water impregnation of water + PCM impregnation did not seem to have any significant effect on the varnish adherence.

\section{Conclusions}

Phase change materials can enhance buildings thermal mass and thus lead to energy savings. This study aimed on assessing the potential of two wood species for impregnation with MPCMs in order to make high thermal mass EWF. Red oak and sugar maple samples were impregnated with PCM microcapsules Nextek $^{\odot} 29$ using water as a solvent.

Heat storage of impregnated red oak samples was measured by DHFMA and was of $7.6 \mathrm{~J} / \mathrm{g}$ over $3{ }^{\circ} \mathrm{C}$. This corresponds to an enhancement of $77 \%$ in comparison with untreated wood. Microcapsules were observed within the impregnated samples by optical reflective microscopy. They were mainly found in the large initial wood vessels of red oak. A small quantity of microcapsules was also found in the small final wood vessels. Sugar maple was found to be harder to impregnate and its heat storage 
enhancement was negligible. Some microcapsules were found in the small vessels of sugar maple but the quantity was insufficient to affect the heating storage of this species. In both species, fibers were too small to contain microcapsules. Vessel size seems to be the determinant so the microcapsules can fill the wood. A limiting factor could be that the microcapsules tend to form aggregates. Some of these aggregates could be too large to fill the small vessels and so, only the large red oak vessels contain a high quantity of MPCM. Enhancing the MCPM dispersion could improve the efficiency of such an impregnation.

Red oak was varnished with a $100 \%$ UV solid wood coating and submitted to pull-off adhesion tests. These tests did not reveal any significant effect of an impregnation on the varnish adherence.

The results presented above suggests that red oak heat storage can be enhanced by filling the wood with MPCM. Water was here used as a solvent but next trials could be conducted with a fluid easier to evaporate, to reduce the drying cost. Another fluid could also have a better affinity with the microcapsules or a higher viscosity and thus deposit a higher percentage of capsule within the wood. Another possibility could be to manufacture a shape-stabilized wood/PCM composite with a polymer that would not require microencapsulation of the PCM.

Author Contributions: D.M., P.B., V.L. and P.L. conceptualized the work and defined the methodology; D.M. did the data curation, the formal analysis, the investigation and wrote the original draft. P.B. operated the funding acquisition and the project administration. P.B., V.L. and P.L. contributed to the resources/supervision/validation.

Funding: This research was funded by Natural Sciences and Engineering Research Council of Canada IRC and CRD grant IRCPJ 461745-12 and RDCPJ 445200-12.

Acknowledgments: The authors are grateful to Natural Sciences and Engineering Research Council of Canada for the financial support through its ICP and CRD programs (IRCPJ 461745-12 and RDCPJ 445200-12) as well as the industrial partners of the NSERC industrial chair on eco-responsible wood construction (CIRCERB).

Conflicts of Interest: The authors declare no conflict of interest.

\section{References}

1. Schultz, T.P.; Nicholas, D.D.; Preston, A.F. Perspective-A brief review of the past, present and future of wood preservation. Pest Manag. Sci. 2007, 63, 784-788. [CrossRef] [PubMed]

2. Sweet, M.S. Fire Performance of Wood: Test Methods and Fire Retardant Treatments; Forest Products Laboratory: Madison, WI, USA, 1993.

3. Song, J.; Chen, C.; Zhu, S.; Zhu, M.; Dai, J.; Ray, U.; Li, Y.; Kuang, Y.; Li, Y.; Quispe, N. Processing bulk natural wood into a high-performance structural material. Nature 2018, 554, 224. [CrossRef]

4. Forest Products Society. Wood Handbook Wood as an Engineering Material; Forest Products Society: Madison, WI, USA, 2010.

5. Shapiro, M.; Feldman, D.; Hawes, D.; Banu, D.J.P.S.J. Thermal storage in drywall using organic phase-change material. Passive Sol. J. 1987, 4, 419-438.

6. Sharma, R.; Ganesan, P.; Tyagi, V.; Metselaar, H.; Sandaran, S.C. Developments in organic solid-liquid phase change materials and their applications in thermal energy storage. Energy Convers. Manag. 2015, 95, 193-228. [CrossRef]

7. Kośny, J.; Yarbrough, D.W.; Riazzi, T.; Leuthold, D.; Smith, J.B.; Bianchi, M. Development and testing of ignition resistant microencapsulated phase change material. Proc. Effstock 2009.

8. Kośny, J. PCM-Enhanced Building Components: An Application of Phase Change Materials in Building Envelopes and Internal Structures; Springer: Berlin, Germany, 2015.

9. Noel, J.; Allred, P.; White, M. Life cycle assessment of two biologically produced phase change materials and their related products. Int. J. Life Cycle Assess. 2015, 20, 367-376. [CrossRef]

10. Zhou, D.; Zhao, C.Y.; Tian, Y. Review on thermal energy storage with phase change materials (PCMs) in building applications. Appl. Energy 2012, 92, 593-605. [CrossRef]

11. Zhou, Z.; Zhang, Z.; Zuo, J.; Huang, K.; Zhang, L. Phase change materials for solar thermal energy storage in residential buildings in cold climate. Renew. Sustain. Energy Rev. 2015, 48, 692-703. [CrossRef]

12. Zalba, B.; Marin, J.; Cabeza, L.; Mehling, H. Free-cooling of buildings with phase change materials. Int. J. Refrig.-Rev. Int. Froid 2004, 27, 839-849. [CrossRef] 
13. Wang, Q.; Wu, R.; Wu, Y.; Zhao, C. Parametric analysis of using PCM walls for heating loads reduction. Energy Build. 2018, 172, 328-336. [CrossRef]

14. Mazzeo, D.; Oliveti, G.; Arcuri, N. Definition of a new set of parameters for the dynamic thermal characterization of PCM layers in the presence of one or more liquid-solid interfaces. Energy Build. 2017, 141, 379-396. [CrossRef]

15. Barreneche, C.; Navarro, L.; de Gracia, A.; Fernandez, A.I.; Cabeza, L.F. In situ thermal and acoustic performance and environmental impact of the introduction of a shape-stabilized PCM layer for building applications. Renew. Energy 2016, 85, 281-286. [CrossRef]

16. Athienitis, A.; Liu, C.; Hawes, D.; Banu, D.; Feldman, D. Investigation of the thermal performance of a passive solar test-room with wall latent heat storage. Build. Environ. 1997, 32, 405-410. [CrossRef]

17. Li, M.; Guo, Q.G.; Nutt, S. Carbon nanotube/paraffin/montmorillonite composite phase change material for thermal energy storage. Sol. Energy 2017, 146, 1-7. [CrossRef] [PubMed]

18. Cho, J.-S.; Kwon, A.; Cho, C.-G. Microencapsulation of octadecane as a phase-change material by interfacial polymerization in an emulsion system. Colloid Polym. Sci. 2002, 280, 260-266. [CrossRef]

19. Hawlader, M.; Uddin, M.; Khin, M.M. Microencapsulated PCM thermal-energy storage system. Appl. Energy 2003, 74, 195-202. [CrossRef]

20. Jamekhorshid, A.; Sadrameli, S.M.; Farid, M. A review of microencapsulation methods of phase change materials (PCMs) as a thermal energy storage (TES) medium. Renew. Sustain. Energy Rev. 2014, 31, 531-542. [CrossRef]

21. Giro-Paloma, J.; Martinez, M.; Cabeza, L.F.; Fernandez, A.I. Types, methods, techniques, and applications for microencapsulated phase change materials (MPCM): A review. Renew. Sustain. Energy Rev. 2016, 53, 1059-1075. [CrossRef]

22. Alkan, C.; Sari, A.; Karaipekli, A.; Uzun, O. Preparation, characterization, and thermal properties of microencapsulated phase change material for thermal energy storage. Sol. Energy Mater. Sol. Cells 2009, 93, 143-147. [CrossRef]

23. Jeong, S.; Jeon, J.; Seo, J.; Lee, J.; Kim, S. Performance evaluation of the microencapsulated PCM for wood-based flooring application. Energy Convers. Manag. 2012, 64, 516-521. [CrossRef]

24. Guo, X.; Cao, J.; Peng, Y.; Liu, R. Incorporation of microencapsulated dodecanol into wood flour/high-density polyethylene composite as a phase change material for thermal energy storage. Mater. Des. 2016, 89, 1325-1334. [CrossRef]

25. Mathis, D.; Blanchet, P.; Landry, V.; Lagière, P. Thermal characterization of bio-based phase changing materials in decorative wood-based panels for thermal energy storage. Green Energy Environ. 2018, in press. [CrossRef]

26. Li, Y.; Li, X.; Liu, D.; Cheng, X.; He, X.; Wu, Y.; Li, X.; Huang, Q. Fabrication and Properties of Polyethylene Glycol-Modified Wood Composite for Energy Storage and Conversion. BioResources 2016, 11, 7790-7802. [CrossRef]

27. Barreneche, C.; Vecstaudza, J.; Bajare, D.; Fernandez, A. PCM/wood composite to store thermal energy in passive building envelopes. Proc. IOP Conf. Ser. Mater. Sci. Eng. 2017, 251, 012111. [CrossRef]

28. Vasco, D.A.; Salinas-Lira, C.; Barra-Reyes, I.; Elustondo, D.M. Kinematic characterization of the pressure-dependent PCM impregnation process for radiata pine wood samples. Eur. J. Wood Wood Prod. 2018, 76, 1461-1469. [CrossRef]

29. Blanchet, P. Caractérisation du comportement des lames de plancher d'ingénierie. Résumé 2004, 2, 2-3.

30. Panshin, A.J.; Zeeuw, C.D. Textbook of Wood Technology. Volume I. Structure, Identification, Uses, and Properties of the Commercial Woods of the United States and Canada; McGraw-Hill Book Company Inc.: New York, NY, USA, 1970.

31. Navi, P.; Heger, F. Comportement Thermo-Hydromécanique du bois: Applications Technologiques et dans les Structures; PPUR Presses Polytechniques: Lausanne, Switzerland, 2005.

32. Jiang, X.; Hou, Q.; Liu, W.; Zhang, H.; Cui, Y.; Wang, X.J.H. Improved permeability of autohydrolyzed poplar sapwood against sodium hydroxide for CMP production. Holzforschung 2018, 72, 347-355. [CrossRef] 